artery, which resulted in multiple neurological symptoms on the right side in addition to Horner's syndrome. ${ }^{2}$ The lesion was therefore in the central or brain stem portion of the cervical sympathetic supply, which invariably produces other neurological abnormalities as well as Horner's syndrome, such as hemicorporeal anhidrosis, ${ }^{3}$ which my patient did not have. The absence of other neurological symptoms and signs, apart from transient headache and slight nausea, in my patient suggested that only the sympathetic nervous system was affected.

During manipulation the forceful thrusts at the base of the neck on the left may have caused a traction or avulsion injury to the white ramus communicans between the first thoracic nerve and the first thoracic or inferior cervical sympathetic ganglion, where it runs under and in front of the head of the first rib; the injury would have been due to forward movement of the left first thoracic vertebral transverse process. Thus the injury was probably in the preganglionic fibres. Accidental or iatrogenic trauma is the commonest cause of preganglionic Horner's syndrome, ${ }^{3}$ and traction injury to the preganglionic fibres, though mild and sustained rather than forceful and quick, was thought to have caused transient Horner's syndrome during an operation. ${ }^{4}$ Transient Horner's syndrome may result from ischaemia of the postganglionic fibres surrounding the carotid arterial supply. ${ }^{5}$

The fact that mishaps may occur should not result in use of manipulation being discouraged; nor does this report necessarily suggest that chiropractic manipulation is more hazardous than medical techniques, although the particular manoeuvre described here may be more liable to problems than some others. This is the first report of isolated Horner's syndrome occurring as a complication of spinal manipulation.

1 Robertson JT. Neck manipulation as a cause of stroke. Stroke 1981;12:1

2 Sherman DG, Hart RG, Easton DJ. Abrupt change in head position and cerebral infarction. Stroke 1981;12:2-6.

3 Smith PG, Dyches TJ, Burde RM. Topographic analysis of Horner's syndrome. Otolaryngol Head Neck Surg 1986;94:451-7.

4 Jaffe TB, McLesky CH. Position-induced Horner's syndrome. Anesthesiology 1982;56:49-50.

5 Zisfein J. Postganglionic Horner's syndrome in carotid artery disease. Mt Sinai $\mathcal{J}$ Med (NY) 1981;48:466-8.

(Accepted 3 September 1987)

North Middlesex Hospital, London N18 1QX

M F GRAYSON, MB, FRCP, consultant rheumatologist

\section{Hazards of compression treatment of the leg: an estimate from Scottish surgeons}

Compression has been used for centuries to manage varicose veins, the postthrombotic syndrome, and leg ulcers, and also in modern times for preventing deep vein thrombosis. Recent improvements in compression bandages and hosiery allow pressures approaching $60 \mathrm{~mm} \mathrm{Hg}$ to be sustained, ${ }^{12}$ with consequent narrowing of the margin between benefit and hazard.

We had observed several cases in which the injudicious use of compression in a limb with occult arterial disease had apparently led to severe skin necrosis and, in a few instances, to amputation. We therefore performed a survey to see if our colleagues had had similar experiences and to discover the extent of the problem.

\section{Methods and results}

All (154) consultants in general surgery in Scotland were asked in a questionnaire about the number of cases of ulcers or necrosis that they had seen in the past five years which were specifically induced or aggravated by compression bandages, elastic stockings, or anti-thromboembolism stockings. They were also asked whether any of these needed subsequent reconstruction of the arterial supply or amputation of the leg.

All 154 surgeons replied. Forty nine (32\%) reported at least one case of damage induced by compression and 32 more than one. Analysis of the positive replies is shown in the table. The damage had necessitated reconstruction of the arteries in seven cases $^{2}$ and amputation in 12 .

\section{Comment}

Like most effective treatments compression has certain dangers. This survey showed that about one third of surgeons in Scotland recognised damage of the leg that was caused by compression. This is probably a considerable underestimate for several reasons; the survey was retrospective and depended on recollection, damage of this kind is often not recognised, and, most importantly, $80 \%$ of patients with leg ulcers are managed entirely in the community. ${ }^{5}$

Compression damage: positive responses

\begin{tabular}{lcc}
\hline & No (\%) of surgeons & No of cases \\
\hline Ulcers/necrosis due to: & $29(19)$ & \\
Compression bandages & $16(10)$ & 73 \\
Elastic stockings & $17(11)$ & 36 \\
Stockings used to prevent embolism & $62(40)$ & 38 \\
\hline Total & & 147
\end{tabular}

As many cases of damage were associated with compression bandages as with graduated support stockings and antiembolism stockings together. Several factors may be relevant. The application of a bandage is more dependent on the operator and the degree of compression more variable than with a stocking. Clinical indications are also different; in particular compression bandaging is widely used to treat leg ulcers. In a detailed study of 600 patients with chronic ulceration we showed that $22 \%$ had measurable impairment of the arterial supply to the ulcerated leg, ${ }^{3}$ and another survey showed such impairment in $31 \% .{ }^{4}$ Our studies showed that the palpation of distal pulses in ulcerated and often oedematous legs is not always reliable. We recommend therefore that unless distal pulses of good volume can be felt, Doppler pressures should be measured in the ankle before treatment with compression. The compression of oedematous legs seems to be particularly hazardous.

Antiembolism stockings were associated with damage in 38 cases. We suggest that if the distal pulses are not palpable the manufacturer's warnings should be heeded and an alternative method of prophylaxis considered. Similar precautions should be taken with elastic stockings, which the survey showed to be associated with 36 cases of damage. Correct fitting and application of both types of stockings are essential.

We conclude that necrosis induced by compression is common in Scotland. While fully recognising the lack of precision in this study, we think that it is vital to draw attention to this serious complication because of the improvements in compression bandages and hosiery and the widespread use of stockings in the prophylaxis of thromboembolism.

Raj TB, Goddard M, Makin GS. How long do compression bandages maintain their pressure during ambulatory treatment of varicose veins? Br 7 Surg 1980;67:122-4.

The Nursing Times 1980; 76:1123-6.

3 Callam MJ, Harper DR, Dale JJ, Ruckley CV. Arterial disease in chronic leg ulceration: an underestimated hazard. Br Med f 1987;294:929-31.

4 Cornwall JV, Dore CJ, Lewis JD. Leg ulcers: epidemiology and aetiology. Br f Surg 1986;73: 693-6.

Callam MJ, Ruckley CV, Harper DR, Dale JJ. Chronic ulceration of the leg: extent of the problem and provision of care. BrMed f 1985;290:1855-6.

(Accepted 15 September 1987)

Vascular Surgery Unit, Royal Infirmary, Edinburgh EH3 9YW

M J CALLAM, FRCSED, senior registrar

C V RUCKLEY, CHM, FRCSED, consultant surgeon

Lothian Health Board

J J DALE, SRN, MSC, senior nurse

Royal Infirmary, Falkirk

D R HARPER, MD, FRCSED, consultant surgeon

Correspondence and requests for reprints to: Mr Ruckley.

\section{Corrections}

\section{A simple test to diagnose iritis}

We regret that an editorial error occurred in this short report by Mr E Mark Talbot ( 3 October, $p$ 812). In the figure the two lower photographs should be above the two upper photographs.

\section{Fatal toxicity of antidepressant drugs in overdose}

We regret that an editorial error occurred in this paper by $\mathrm{Mr}$ Simon Cassidy and Dr John Henry (24 October, 1021 ). In table II, in the column headed No of deaths per million prescriptions ( $95 \%$ confidence intervals), the figure for lofepramine should be 0.0 and not $3 \cdot 7$. 